Психология. Журнал Высшей школы экономики.

2020. T. 17. № 4. C. 822-832. DOI: 10.17323/1813-8918-2020-4-822-832

\title{
ПРОТИВОРЕЧИВОСТЬ ТОЛЕРАНТНОСТИ В КОНТЕКСТЕ ЭТИКИ АВТОНОМИИ И ЭТИКИ СООБЩЕСТВА
}

\author{
О.А. СЫЧЕВ ${ }^{\mathrm{a}}$, И.Н. ПРОТАСОВА
}

${ }^{a}$ Алтайский государственный гуманитарно-педагогический университет имени В.М. Шукиина, 659333, Россия, Алтайский край, Бийск, ул. Короленко, д. 53

\begin{abstract}
Резюме
В статье представлены результаты анализа толерантности в ее взаимосвязях с моралью на основе теории моральных оснований Дж. Хайдта. Обзор литературы показал, что общим для многих исследователей является признание противоречивости толерантности, в том числе в моральном аспекте. С точки зрения теории моральных оснований такая противоречивость может быть следствием того, что толерантность хорошо согласуется с этикой автономии, включающей нормы заботы и справедливости, но при этом противоречит этике сообщества, включающей нормы лояльности группе, уважения и чистоты. Подобное противоречие должно заметно проявляться, когда речь идет о толерантности по отношению к потенциально опасным группам. Для проверки этой гипотезы было проведено исследование с участием 202 студентов (в возрасте от 18 до 46 лет, 36\% мужчин), ответивших на вопросы методики многофакторного исследования толерантности (МИТ) и опросника моральных оснований (MFQ). C помощью эксплораторного факторного анализа шкал МИТ были выделены два типа объектов толерантности: «уязвимые» группы (старшие, маргиналы, больные, противоположный пол) и «опасные» группы (религиозные, национальные, чужаки, преступники). Для проверки гипотезы о противоречивых отношениях толерантности с этикой автономии и этикой сообщества была построена структурная модель, в которой этика автономии была прямо связана с толерантным отношением к уязвимым и опасным группам, в то время как этика сообщества связана с интолерантностью в отношении опасных групп. Хорошая согласованность этой модели с данными позволяет сделать вывод о том, что этика автономии поддерживает толерантность по отношению к любым группам, в то время как этика сообщества противоречит толерантному отношению к опасным группам. Разнонаправленные связи толерантности с моральными основаниями раскрывают противоречивость толерантности в контексте этики автономии и этики сообщества.
\end{abstract}

Ключевые слова: межгрупповая толерантность, интолерантность, теория моральных оснований, этика автономии, этика сообщества.

Работа выполнена при финансовой поддержке РФФИ, проект № 18-013-00119 «Ценностные и моральные основы социального мировоззрения молодежи». 


\section{Введение}

Этнокультурное разнообразие современного мира в сочетании с высокой мобильностью населения превратило контакты с представителями другой национальности, конфессии, культуры в обыденное явление. Нетерпимое, интолерантное отношение к представителям других национальностей и культур в этих условиях может создавать благоприятную почву для конфликтов. Запросы социальной практики привели к росту интереса психологов к межгрупповой толерантности, характеризующей отношение к иным социальным группам, отличающимся по различным признакам: национальности, конфессиональной принадлежности, полу, возрасту и т.п. Под толерантностью при этом понимается «позиция признания иных ценностей, взглядов, обычаев как равноправных с привычными "своими" ценностями, взглядами и обычаями, вне зависимости от степени согласия с ними» (Леонтьев, 2009, с. 8).

Актуальным и перспективным представляется дифферениированный по объектам анализ толерантности, предложенный Д.А. Леонтьевым (Там же, с. 9). Он может оказаться полезным при решении вопроса о разумных пределах толерантности: является ли оправданной толерантность к потенциально опасным группам, которые в будущем могут нести угрозу безопасности? При этом существенным представляется критерий наличия и величины угрозы, исходящей от другой группы. Неслучайно для характеристики различных проявлений межгрупповой интолерантности нередко используется корень «фобия» (например, ксенофобия, этнофобии и др. - Асмолов и др., 2001), указывающий на наличие страха, связанного с восприятием реальной или мнимой опасности, угрозы, исходящей от объекта. Оценка угрозы может оказаться различной для разных людей в зависимости от сильной или слабой модели вреда (Хомяков, 2011): для одних эта угроза может выглядеть мнимой, в то время как для других - вполне реальной.

Включение в анализ толерантности субъективной оценки опасности чужой группы помогает глубже понять противоречивость толерантности, которую указывают в качестве ее фундаментальной характеристики. Эта противоречивость ярко проявляется именно в моральной плоскости: «С одной стороны, имеется то, что кажется нам морально ошибочным, а с другой - мы как субъекты морали должны допускать существование этого ошибочного» (Там же, c. 25). При анализе межгрупповой толерантности обнаруживается аналогичное частное противоречие: наличие иной группы, представляющей мнимую или реальную угрозу своей группе, делает морально оправданной защиту от этой угрозы (например, в форме отторжения и осуждения иной группы), в то время как другие нормы морали позволяют принимать и признавать другую группу в качестве равноправной.

Для анализа этого противоречия в категориях психологии морали представляется продуктивным обращение к теории моральных оснований (ТМО), в которой предлагается лаконичное, но достаточно полное описание базовых составляющих моральной сферы с помощью пяти моральных оснований. Понятие моральных оснований используется для обозначения базовых 
составляющих морали, выступающих как обобщенные критерии (основания) нравственной оценки различных поступков и событий (Graham et al., 2011).

Основные положения теории моральных оснований уже рассматривались в русскоязычных публикациях (Козлова, Козлов, 2016; Сычев и др., 2016, 2018). Для нашего исследования существенным представляется разделение моральных оснований на два типа. К первому типу - индивидуализирующих моральных оснований - относятся забота и справедливость, включающие нормы, ориентированные на защиту прав и свобод личности. Ко второму типу - сплачивающих, связанному с отношением индивида к своей группе и участием в ее жизни, относятся три моральных основания: лояльность группе, уважение к авторитетам и чистота/почитание святынь. Данная типология является развитием концепции Р.А. Шведера, выделившего три основных тематических кластера: этики автономии, этики сообщества и этики божественного (Shweder et al., 1997). Словосочетания этика автономии и этика сообщества, более естественно звучащие на русском языке, стали использоваться в отечественных публикациях в качестве синонимов индивидуализирующих и сплачивающих моральных оснований. Необходимо отметить, что проблемы в эмпирическом подтверждении пятифакторной структуры опросника MFQ привели к тому, что распространенной практикой стало преимущественное использование обобщенных показателей по двум типам моральных оснований (Hadarics, Kende, 2018a, 2018b).

Толерантность обычно рассматривается в качестве либеральной ценности (Асмолов и др., 2001), поэтому в контексте нашего исследования интерес представляют данные о различиях в профиле моральных оснований у либералов и консерваторов (Graham et al., 2009). Консервативные убеждения сочетаются с высокой оценкой как индивидуалистических, так и сплачивающих моральных оснований, в то время как для лиц с либеральными взглядами характерна низкая оценка сплачивающих моральных оснований. Эти данные позволяют предполагать обратную связь толерантности с моральными основаниями, образующими этику сообщества.

Немногочисленные исследования связи моральных оснований с отношением к другим группам показали важную, хотя и неодинаковую роль разных моральных оснований. В проведенном в Венгрии исследовании была проанализирована связь моральных оснований с позитивными (оказание помощи) и негативными (причинение вреда) намерениями по отношению к аутгруппе мусульманам (Hadarics, Kende, 2018a). Была установлена обратная связь индивидуализирующих моральных оснований с негативными намерениями и прямая связь с позитивными. Сплачивающие моральные основания, напротив, показали прямую связь с негативными намерениями и обратную - с позитивными. В другом исследовании тех же авторов было выявлено, что индивидуализирующие моральные основания ослабляют предубеждения по отношению к любым группам, в то время как сплачивающие моральные основания избирательно усиливают предубеждения по отношению к чуждым (евреи, чернокожие, иммигранты, гомосексуалисты и т.п.) и опасным (преступники, наркоманы, алкоголики, проститутки) группам, не оказывая влияния на 
установки в отношении уязвимых групп (безработные, бездомные, пенсионеры, инвалиды) (Hadarics, Kende, 2018b).

Рассмотренные сведения позволяют предположить, что одной из причин внутренней противоречивости толерантности может быть противоречивый характер ее отношений с «этикой автономии» и «этикой сообщества». Наличие потенциально угрожающей группы, с точки зрения норм этики сообщества, требует защиты (отвержения или осуждения чужой группы), а с точки зрения норм этики автономии - толерантного к ней отношения. Противоречивость толерантности должна проявляться наиболее ярко в отношении групп, отличающихся друг от друга по критерию опасности.

\section{Организация и методы исследования}

\section{Цель и гипотезь}

Целью исследования является анализ связи «этики автономии» и «этики сообщества» с толерантным отношением к разным социальным группам, отличающимся друг от друга наличием потенциальной угрозы. Проверялись следующие эмпирические гипотезы:

1. Этика автономии, включающая нормы заботы и справедливости, поддерживает толерантность к любым группам.

2. Этика сообщества, включающая нормы лояльности группе, уважения и чистоты, противоречит толерантности по отношению к потенциально опасным группам, которые могут представлять угрозу обществу.

\section{Участники}

В исследовании приняли участие 202 студента 1-2-го курсов заочного отделения АГГПУ им. В. М. Шукшина, среди них 36\% мужчин. Возраст варьировался от 18 до 46 лет $(M=23.08, S D=3.92)$. Участники заполняли опросник в группах.

\section{Методики}

Для диагностики моральной сферы использовался опросник моральных оснований Дж. Грэхема и др. (Graham et al., 2011) в адаптации О.А. Сычева, И.Н. Протасовой и К.И. Белоусова (Сычев и др., 2018). Опросник состоит из двух частей по 15 заданий, образующих пять шкал первого уровня, соответствующих моральным основаниям: «Забота», «Справедливость», «Лояльность», «Уважение», «Чистота». При обработке результатов подсчитываются средние баллы для каждого испытуемого по шкалам первого уровня, а также средние показатели по шкалам второго уровня: этики автономии и этики сообщества. В данном исследовании в опубликованную ранее версию методики (Там же) были внесены отдельные изменения, направленные на уточнение формулировок с целью повышения внутренней согласованности шкал. 
Коэффициенты надежности ( $\alpha$-Кронбаха) использовавшихся в данном исследовании шкал «Этика автономии» и «Этика сообщества» составили 0.81 и 0.83 соответственно.

Для диагностики толерантности использовался опросник «Многофакторное исследование толерантности» (МИТ) Ю.Д. Бабаевой и П.А. Сабадоша (2008). Опросник МИТ предназначен для диагностики толерантного отношения к различным объектам и индивидуально-психологических характеристик, обусловливающих это отношение. Опросник МИТ содержит 60 пунктов, образующих два ряда шкал. Первый ряд состоит из десяти шкал, каждая из которых измеряет толерантность к определенному «объекту» (национальность, религия, нормы поведения и др.). В другой ряд входят четыре шкалы, отражающие совокупность индивидуально-психологических характеристик респондента, служащих предпосылками толерантного поведения. Поскольку объектом нашего исследования является межгрупповая толерантность, в данном исследовании использовались только восемь объектных шкал данной методики, характеризующих отношение к другим группам. Методика МИТ имеет приемлемые психометрические характеристики (Бабаева, Сабадош, 2008), а факторная структура опросника была подтверждена с помощью многочертной-многометодной модели (Митина и др., 2011).

\section{Методы анализа}

Количественный анализ результатов проводился с помощью программ $\mathrm{R}$ (пакеты «psych», «QuantPsyc») и Mplus 7, использовались методы регрессионного и факторного анализа, а также структурное линейное моделирование.

\section{Результаты}

Чтобы убедиться в возможности выделения толерантного отношения к опасным группам в качестве особого компонента толерантности, был выполнен эксплораторный факторный анализ (ЭФА) шкал МИТ, результаты которого представлены в таблице 1. О пригодности наших данных для ЭФА свидетельствуют значения соответствующих критериев (критерий Бартлетта $\left.\chi^{2}(28)=342 ; p<0.001 ; \mathrm{KMO}=0.786\right)$.

Первый фактор (см. таблицу 1) объединяет группы, практически не представляющие угрозы: маргиналы, старшие, больные, а также лиц противоположного пола. Второй фактор включает группы, которые отличаются по религиозному и национальному признаку, а также преступников и чужаков. В отличие от первого фактора эти группы, по-видимому, воспринимаются чуждыми, представляющими потенциальную угрозу для общества и его ценностей. В дальнейшем с некоторой долей условности мы будем называть эти факторы «уязвимыми» и «опасными» группами.

Чтобы проанализировать связь толерантности к этим группам с «этикой автономии» и «этикой сообщества», были построены две регрессионные модели, в которых в качестве зависимой переменной выступали факторные оценки, 
отражающие толерантность в отношении уязвимых групп и опасных групп, а в качестве независимых переменных - «этика автономии» и «этика сообщества» (см. таблицу 2). О соответствии данных предположениям регрессионного анализа свидетельствует отсутствие отклонений от нормального распределения остатков (критерий Шапиро-Уилка $\mathrm{W}>0.994, p>0.7$ ), а также их гомоскедастичность и отсутствие выбросов на диаграмме. Значения стандартизованных регрессионных коэффициентов подтверждают, что «этика автономии» прямо связана с толерантностью к уязвимым и опасным группам, в то время как «этика сообщества» обратно связана с толерантностью в отношении опасных групп.

Таблица 1

Результаты эксплораторного факторного анализа восьми объектных шкал МИТ ( $\mathrm{N}=202$, метод минимальных остатков, вращение «промакс»)

\begin{tabular}{|l|c|c|}
\hline \multirow{2}{*}{ Состав групп } & \multicolumn{2}{|c|}{ Факторные нагрузки } \\
\cline { 2 - 3 } & Фактор 1 & Фактор 2 \\
\hline Маргиналы & $\mathbf{0 . 8 9}$ & -0.13 \\
\hline Старшие & $\mathbf{0 . 6 6}$ & 0.03 \\
\hline Больные & $\mathbf{0 . 5 6}$ & -0.05 \\
\hline Противоположный пол & $\mathbf{0 . 4 8}$ & 0.08 \\
\hline Религия & -0.25 & $\mathbf{0 . 8 8}$ \\
\hline Преступники & 0.18 & $\mathbf{0 . 5 0}$ \\
\hline Национальность & 0.09 & $\mathbf{0 . 3 9}$ \\
\hline Чужаки & 0.22 & $\mathbf{0 . 3 1}$ \\
\hline Доля оббясняемой дисперсии & 0.23 & 0.15 \\
\hline Корреляция между факторами & & 0.74 \\
\hline
\end{tabular}

Примечание. Факторные нагрузки, превышающие 0.30 , отмечены полужирным шрифтом.

Таблица 2

Результаты регрессионного анализа связи толерантности к различным группам с этикой автономии и этикой сообщества $(\mathrm{N}=202)$

\begin{tabular}{|l|c|c|c|c|c|}
\hline \multirow{2}{*}{ Зависимая переменная } & \multicolumn{2}{|l|}{$\begin{array}{c}\text { Стандартизованные регрес- } \\
\text { сионные коэффициенты } \boldsymbol{\beta} \\
\text { (уровень значимости })\end{array}$} & \multicolumn{3}{|l|}{ Характеристики моделей } \\
\cline { 2 - 6 } & $\begin{array}{c}\text { Этика } \\
\text { автономии }\end{array}$ & $\begin{array}{c}\text { Этика } \\
\text { сообщества }\end{array}$ & $R^{2}$ & $\mathrm{~F}(2 ; 199)$ & $p$ \\
\hline $\begin{array}{l}\text { Толерантность в отношении } \\
\text { уязвимых групп }\end{array}$ & $\begin{array}{c}0.35 \\
(p<0.001)\end{array}$ & $\begin{array}{c}-0.11 \\
(p=0.214)\end{array}$ & 0.09 & 9.35 & $<0.001$ \\
\hline $\begin{array}{l}\text { Толерантность в отношении } \\
\text { опасных групп }\end{array}$ & $\begin{array}{c}0.44 \\
(p<0.001)\end{array}$ & $\begin{array}{c}-0.36 \\
(p<0.001)\end{array}$ & 0.12 & 13.58 & $<0.001$ \\
\hline
\end{tabular}


Для проверки гипотезы с помощью конфирматорных методов на следующем этапе анализа было проведено линейное структурное моделирование отношений между двумя факторами толерантности и моральными основаниями с использованием робастного алгоритма MLR. Была построена структурная модель, в которой шкалы толерантности к разным группам на основе результатов ЭФА были объединены в два фактора. В качестве предикторов факторов толерантности использовались агрегированные переменные «этика автономии» и «этика сообщества». Анализ исходной модели показал, что путевой коэффициент связи между этикой сообщества и толерантностью к уязвимым группам не является статистически значимым ( $\beta=-0.053 ; p=0.62)$, поэтому данный путь был исключен. В результате была получена представленная на рисунке 1 модель, которая продемонстрировала хорошее соответствие данным: $\chi^{2}=51.89 ; d f=32 ; p=0.015 ; C F I=0.941 ; N N F I=0.919 ; R M S E A=0.055$; $90 \%$-ный доверительный интервал для RMSEA: 0.025-0.082; PCLOSE = 0.347; $N=202$.

Приведенная на рисунке 1 модель иллюстрирует различия в связях толерантности с этикой автономии и этикой сообщества. Этика автономии хорошо согласуется с толерантностью к различным группам, в то время как этика сообщества противоречит толерантности в отношении тех групп, которые потенциально несут угрозу обществу.

\section{Обсуждение}

Проведенный анализ связей этики автономии и этики сообщества с толерантностью по отношению к разным группам показал, что эти связи являются

Рисунок 1

Структурная модель связей толерантности к «уязвимым» и «опасным» группам с этикой автономии и этикой сообщества (все путевые коэффициенты стандартизованы и статистически значимы при $p<0.01$, остатки опущены для упрощения рисунка)

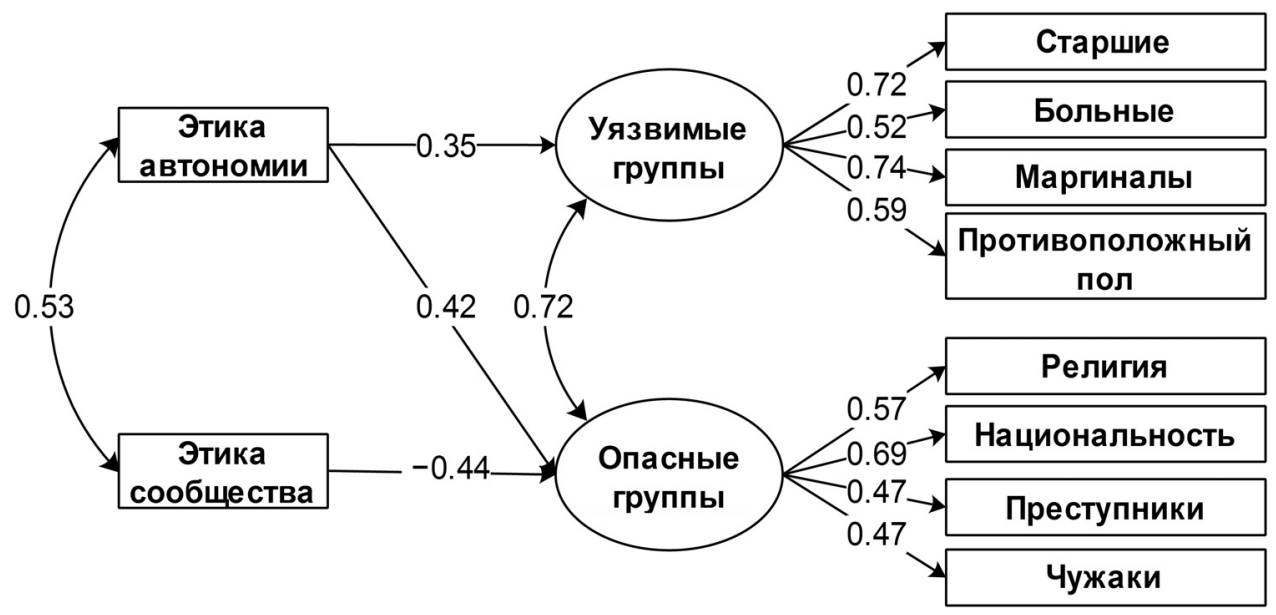


противоречивыми. Несмотря на хорошую согласованность разных проявлений толерантности, имеются основания для выделения как минимум двух ее типов: толерантность по отношению к уязвимым группам и толерантность по отношению к опасным группам.

Полученные результаты подтвердили гипотезы о том, что этика автономии поддерживает толерантность к любым группам, в то время как этика сообщества противоречит толерантности по отношению к потенциально опасным группам. Эти результаты, полученные в корреляционном исследовании, не позволяют с достаточной строгостью сделать выводы об их причинно-следственной связи. Вполне вероятным представляется наличие общих факторов, оказывающих влияние на толерантность и этику автономии. С уверенностью можно утверждать, что этика автономии сопутствует толерантности и, вероятно, поддерживает ее, но не обязательно является ее причиной.

Наше исследование подтверждает выводы том, что индивидуализирующие моральные основания ослабляют предубеждения по отношению к любым группам, в то время как сплачивающие моральные основания, напротив, усиливают предубеждения по отношению к чуждым и опасным группам и не оказывают влияния на установки в отношении уязвимых групп (Hadarics, Kende, $2018 b)$. Наши результаты также хорошо согласуются с данными о различной роли сплачивающих моральных оснований в либеральных и консервативных политических воззрениях (Graham et al., 2009), если принять во внимание связь толерантности с либеральной идеологией (Асмолов и др., 2001).

Ограничения исследования связаны с использованием небольшого набора объектов толерантности, не включающего некоторых групп, зачастую вызывающих интолерантное отношение в нашем обществе. Мы планируем провести анализ толерантного/интолерантного отношения к другим важным группам в моральном контексте.

Вывод о том, что толерантность выступает в качестве противоречивого конструкта, связанного с этикой автономии и этикой сообщества разнонаправленными связями, представляет не только теоретический интерес. Проведенный анализ этого явления в контексте норм этики автономии и этики сообщества помогает глубже понять причины неоднозначного отношения к толерантности в обществе.

\section{Литература}

Асмолов, А. Г., Солдатова, Г. У., Шайгерова, Л. А. (2001). О смыслах понятия «толерантность». Век толерантности. Научно-публицистический вестник, 1-2, 8-19.

Бабаева, Ю. Д., Сабадош, П. А. (2008). Руководство по использованию опросника «Многофакторное исследование толерантности». М.: МАТИ.

Козлова, М. А., Козлов, А. И. (2016). Истоки морали, ориентированной на индивида и группу: социально-психологический и естественно-научный аспекты. Психологический журнал, 37(3), 60-70.

Леонтьев, Д. А. (2009). К операционализации понятия «толерантность». Вопросы психологии, 5 , $3-16$. 
Митина, О. В., Бабаева, Ю. Д., Сабадош, П. А. (2011). Психометрический анализ опросника «Многофакторное исследование толерантности» с использованием многочертной-многометодной модели. Вестник Московского университета. Серия 14. Психология, 1, 124-140.

Сычев, О. А., Беспалов, А. М., Прудникова, М. М., Власов, М. С. (2016). Особенности моральных оснований у монгольских, немецких и российских подростков. Культурно-историческая психология, 12(1), 85-96. doi:10.17759/chp.2016120109

Сычев, О. А., Протасова, И. Н., Белоусов, К. И. (2018). Диагностика моральных оснований: апробация русскоязычной версии опросника MFQ. Российский психологический журнал, 15(3), 88-115. doi:10.21702/rpj.2018.3.5

Хомяков, М. Б. (2011). Толерантность и ее границы. Наииональный психологический журнал, 2(6), 25-33.

Ссылки на зарубежные источники см. в разделе References после англоязычного блока.

Сычев Олег Анатольевич - научный сотрудник, Алтайский государственный гуманитарно-педагогический университет имени В.М. Шукшина, кандидат психологических наук. Сфера научных интересов: позитивная психология, мотивация, оптимизм, мораль, математические методы в психологии.

Контакты: osn1@mail.ru

Протасова Ирина Николаевна - доцент, кафедра психологии и педагогики, Алтайский государственный гуманитарно-педагогический университет имени В.М. Шукшина, кандидат психологических наук.

Сфера научных интересов: педагогическая психология, психология личности.

Контакты: protasovain@mail.ru

\title{
Inconsistency of Intergroup Tolerance in the Context of Autonomy and Community Ethics
}

\author{
O.A. Sychev ${ }^{\text {a }}$ I.N. Protasova ${ }^{a}$
}

${ }^{a}$ Altai State Humanities Pedagogical University, 53 Korolenko Str., Altai region, Biysk, 659333, Russian Federation

\begin{abstract}
The paper analyzes the relationships of intergroup tolerance with morality on the basis of the moral foundations theory by J. Haidt. Literature review showed that many researchers view tolerance as an internally inconsistent construct including its moral inconsistency. From the point of view of the moral foundations theory, inconsistency of tolerance may be due to the different relations with individualizing and binding moral foundations: tolerance is consistent with individualizing moral foundations (autonomy ethics) and inconsistent with binding moral foundations (community ethics). Such inconsistency has to manifest itself in the case of tolerance towards potentially dangerous groups. This hypothesis was tested in our study, which included 202 university students aged 18-46 (36\% males). They answered the questions of "Moral foundations questionnaire" (MFQ by Graham) and "Multifactor inventory of tolerance" (MIT by
\end{abstract}


Babaeva \& Sabadosh). Using exploratory factor analysis, we discovered two types of groups: derogated (elder, sick, marginal people, and opposite sex) and dangerous groups (people of different religiosity, nationality, criminals, and strangers). To test the hypothesis we constructed the structural model, where the autonomy ethics was positively correlated with tolerance towards derogated and dangerous groups, while community ethics was negatively correlated with tolerance towards dangerous groups. Good fit of this model to our data lets us to conclude that autonomy ethics is consistent with tolerance towards any group while community ethics is inconsistent with tolerance towards dangerous groups. These correlations between tolerance and moral foundations discover the fundamental inconsistency of tolerance in the context of autonomy and community ethics.

Keywords: intergroup tolerance, intolerance, moral foundations theory, autonomy ethics, community ethics.

\section{References}

Asmolov, A. G., Soldatova, G. U., \& Shaigerova, L. A. (2001). O smyslakh ponyatiya "tolerantnost”" [About meanings of the concept "tolerance"]. Vek Tolerantnosti. Nauchno-publitsisticheskii Vestnik, 1-2, 8-18. (in Russian)

Babaeva, Y. D., \& Sabadosh, P. A. (2008). Rukovodstvo po ispol'zovaniyu oprosnika "Mnogofaktornoe issledovanie tolerantnosti" [Manual for the "Multifactor Inventory of Tolerance"]. Moscow: MATI. (in Russian)

Graham, J., Haidt, J., \& Nosek, B. A. (2009). Liberals and conservatives rely on different sets of moral foundations. Journal of Personality and Social Psychology, 96(5), 1029-1046. doi:10.1037/a0015141

Graham, J., Nosek, B. A., Haidt, J., Iyer, R., Koleva, S., \& Ditto, P. H. (2011). Mapping the moral domain. Journal of Personality and Social Psychology, 101, 366-385. doi:10.1037/a0021847

Hadarics, M., \& Kende, A. (2018, a). Moral foundations of positive and negative intergroup behavior: Moral exclusion fills the gap. International Journal of Intercultural Relations, 64, 67-76. doi:10.1016/j.ijintrel.2018.03.006

Hadarics, M., \& Kende, A. (2018, b). The dimensions of generalized prejudice within the dual-process model: the mediating role of moral foundations. Current Psychology, 37(4), 731-739. doi:10.1007/s12144-016-9544-x

Khomyakov, M. B. (2011). Tolerance and its boundaries. National Psychological Journal, 2(6), 25-33. (in Russian)

Kozlova, M. A., \& Kozlov, A. I. (2016). The origins of individual-oriented and group-oriented morality: social-psychological and scientific aspects. Psikhologicheskii Zhurnal, 37(3), 60-70. (in Russian)

Leontiev, D. A. (2009). Towards an operational definition of tolerance. Voprosy Psikhologii, 5, 3-16. (in Russian)

Mitina, O. V., Babayeva, Yu. D., \& Sabadosh, P. A. (2011). Psychometric analysis of the "Multifactor inventory of tolerance" using multi-trait multimethod model. Moscow University Psychology Bulletin, 1, 124-140. (in Russian)

Shweder, R. A., Much, N. C., Mahapatra, M., \& Park, L. (1997). The "big three" of morality (autonomy, community, divinity) and the "big three" explanations of suffering. In A. M. Brandt \& P. Rozin (Eds.), Morality and health (pp. 119-169). New York: Taylor \& Frances/Routledge. 
Sychev, O. A., Bespalov, A. M., Prudnikova, M. M., \& Vlasov, M. S. (2016). Features of moral foundations in Mongol, German and Russian adolescents. Kul'turno-istoricheskaya psikhologiya [CulturalHistorical Psychology], 12(1), 85-96. doi:10.17759/chp.2016120109. (in Russian)

Sychev, O., Protasova, I., \& Belousov, K. (2018). Diagnosing moral foundations: Testing of the Russian version of the Moral Foundations Questionnaire. Russian Psychological Journal, 15(3), 88-115. doi:10.21702/rpj.2018.3.5 (in Russian)

Oleg A. Sychev - Associate Professor, Altai State Humanities Pedagogical University, PhD in Psychology.

Research Area: positive psychology, motivation, optimism, statistical methods in psychology.

E-mail: osn1@mail.ru

Irina N. Protasova - Associate Professor, Altai State Humanities Pedagogical University, PhD in Psychology.

Research Area: educational psychology, personality psychology.

E-mail: protasovain@mail.ru

Правила подачи статей и подписки можно найти на сайте журнала: http://psy-journal.hse.ru

Свидетельство о регистрации средства массовой информации ПИ № ФС77-66610 от 08 августа 2016 г. зарегистрировано Федеральной службой по надзору в сфере связи, информационных технологий и массовых коммуникаций (РОСКОМНАДЗОР).

Адрес издателя и распространителя

Фактический: 117418, Москва, ул. Профсоюзная, 33, к. 4, Издательский дом НИУ ВШЭ

Тел. +7(495) 772-95-90 доб. 15298

Почтовый: 101000, Москва, ул. Мясницкая, д. 20

Тел. +7(495) 772-95-90, E-mail: id.hse@mail.ru

Формат 70х100/16. Тираж 250 экз. Печ. л. 14 